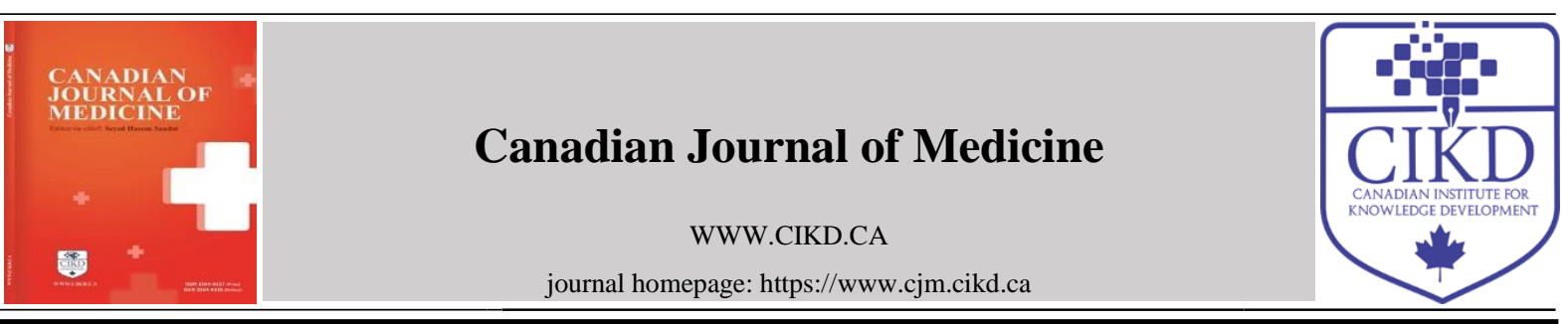

\title{
Study on Phytochemical Screening and Antimicrobial Activity of Adhatoda Vasica
}

\author{
Avani Gohel $^{1}$, Vijay Upadhye ${ }^{2 *}$, Tarun K Upadhyay ${ }^{3}$, Esha Rami ${ }^{4}$, Rakeshkumar \\ Panchal $^{5}$, Suraj Jadhav ${ }^{6}$, Rajesh Dhakane ${ }^{7}$, Vijay Kele ${ }^{8}$
}

${ }^{1,2}$ Departemnt of Microbiology, Parul Institute of Applied Science, Parul University, Vadodara, Gujarat, India

${ }^{3,4}$ Department of Biotechnology, Parul Institute of Applied Science, Parul University, Vadodara, Gujarat, India ${ }^{5}$ Department of Microbiology and Biotechnology, University School of Sciences, Gujarat University, Ahmadabad, Gujarat, India

${ }^{6}$ Department of Nanoscience and Technology, Yashavantrao chavan institute of science, satara, Maharashtra, India

${ }^{7}$ Department of Microbiology, Jayawantrao Sawant College of Commerce and Science, Hadapsar, Pune, Maharashtra, India

${ }^{8}$ Departement of Dairy Technology, Parul Institute of Technology (PIT), Parul University, Vadodara, Gujara, India

\section{Keywords:}

Adhatoda vasica,

Phytochemicals,

Antimicrobial activity,

Broth dilution method

\section{Received}

25 May 2021

Received in revised form

12 June 2021

Accepted

06 July 2021

*Correspondence:

dr.vijaysemilo@gmail.com

\begin{abstract}
Vasaka or Adhatoda vasica (L.) Nees is a well-known plant medication in Ayurvedic and Unani medicine. Cough, whooping cough, cold, and clinging phlegm in the mouth, throat, chest, or breast have been traditionally treated using Adhatoda vasica nees. The present study aimed to evaluate Adhatoda vasica's phytochemical analysis and antimicrobial activity. The preliminary phytochemical screening of alkaloids, steroids, saponins, phenols, and terpenoid yielded positive results. The antibacterial activity of ethanol and leaf extracts of Adhatoda vasica was investigated in this study. Based on the data presented herein, the largest zone of inhibition was found to be against Pseudomonas aeruginosa. The antifungal activity of Aspergillus clavatus was proven to have the maximum zone of inhibition. As a result, the current method may be effective in identifying new bioactive compound for the development of novel medications. Thus, it may be used as a strong antimicrobial agent against Pseudomonas aeruginosa pathogens.
\end{abstract}


Medicinal plants, which are the basis of traditional medicine, have been the subject of much pharmacological research in recent decades. Since ancient times, higher plants have played a controlling role in preserving human health as suppliers of therapeutic chemicals. Over $50 \%$ of all modern clinical drugs are of natural product origin, and natural products play an important role in drug development programs in the pharmaceutical industry [1]. Adhatoda vasica have been useful for years in daily life to treated diseases all over the world. Adhatoda vasica belonging to the Acantharean family is found in India [2]; the leaves are of dark green colors and pale yellow below. The flowers are typical, white, arrange in a pedunculated spike [3]. Adhatoda vasica native range is Asia and is a well-known plant in Ayurveda and Unani systems of medicinal plant. Various parts of this plant have been used to treat several ailments as herbal remedies for many porpoises, e.g., cold, cough, whooping cough, chronic bronchitis, fever, jaundice asthma as a sedative expectorant, diarrhea, and dysentery, as well as inflammatory rheumatic diseases. The roots, leaves, and flowers of the plant are used to remove volatile oils and alkaloids, which have great medicinal importance [3]. The local practitioners use many medicinal plants for treatment of infectious diseases like pneumonia. In many cases, pneumonia is treated at home. It frequently cleared up in 2 to 3 weeks. But older adults, babies, and immune-compromised patients may develop significant complications. Literature survey revealed that the leaves of Adhatoda vasica contain many secondary metabolites and phytochemicals [4]. Several plants have been reported to have antimicrobial activity [5]. Pneumonia has bacterial, viral, fungal, and other primary causes [6]. Medicinal plants are considered a potential source of new compounds of therapeutic value and important sources of new compounds in drug development [7]. These plants make many chemical compounds to protect themselves against fungi, and bacteria, this act in the same way on the human body as allopathic drugs $[8,9]$. The different health benefits of Adhatoda vasicaare are shown in Figure 1.

\section{Health Benefits Of Vasaka (Malabar Nut)}

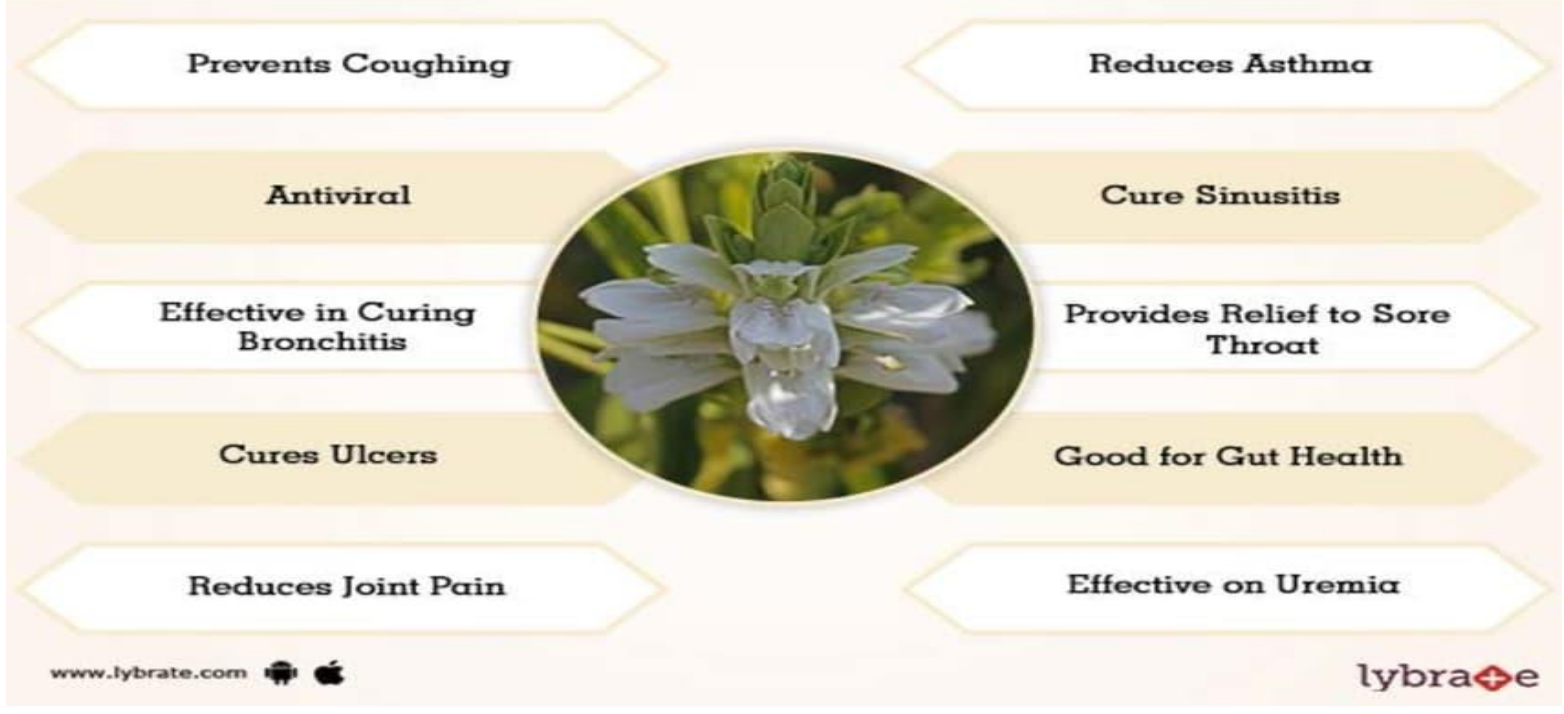

Figure 1.Application of Adhatoda vasica [11] 


\section{Materials and Methods}

The leaves of the plant Adhatoda vasica were collected from the open fields of Kareli baug, Vadodara District, Gujarat, India. The fresh leaves were recognized and validated in the college of Agriculture of Parul University. The fresh leaves were dried for 10 days in sunlight. The powdered sample was stored in a bottle at room temperature before analysis.

\section{Method}

Antimicrobial studies of Adhatoda vasica have been performed in the Micro care lab, Surat. Zinc acetate dehydrate (99\% purity), and sodium hydroxide (Pellet 99\%) was used as introductory materials supplied by Sigma-Aldrich chemicals.

\section{Preparation of Plant Extract}

The powder sample of Adhatoda vasica and ethanol was extracted by using the Soxhlet apparatus. First, the extract of selected plant material in solvents such as ethanol was prepared. Then, the $30 \mathrm{gms}$ of dried powder were extracted with $250 \mathrm{ml}$ solvent using the Soxhlet apparatus to complete eight cycles. The ethanol extracts were lyophilized and stored in $4^{\mathrm{O}} \mathrm{C}$. The resulting extract was sent to NABL Accredited micro care lab of Surat.

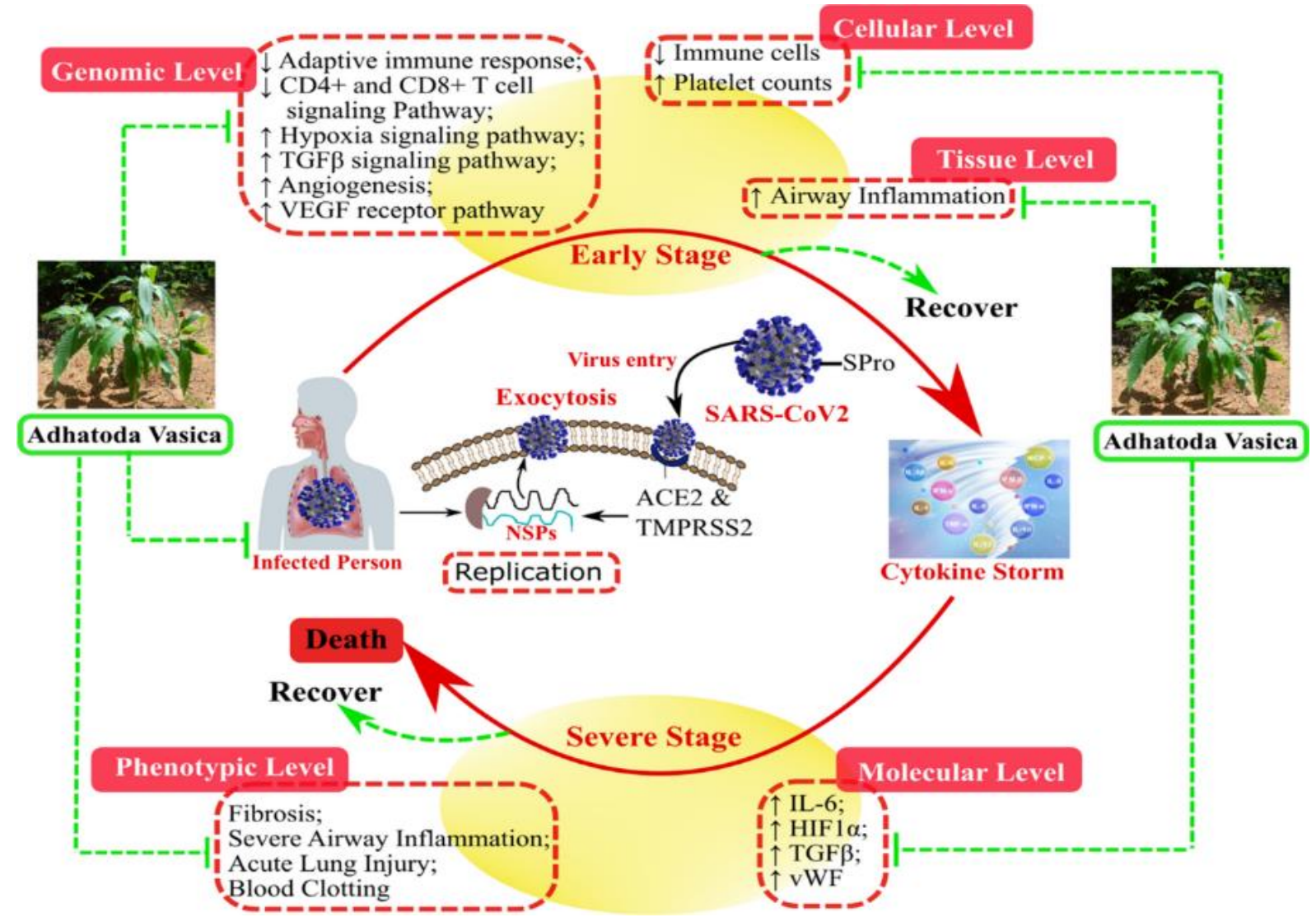

Figure 2. Diagrammatic representation of multidimensional effect of Adhatoda vasica-Inflammatory features of the lung during the early and severe phase of COVID-19[12] 


\section{Phytochemical Screening Tests}

\section{Test for alkaloids}

In this regard, $1 \mathrm{ml}$ of extract sample and $1 \mathrm{ml}$ of Mayer's reagent were added. As a result, the formation of whitish-yellow or cream-colored precipitate exhibits the presence of alkaloids.

\section{Test for steroids}

$1 \mathrm{ml}$ of extract sample, $2 \mathrm{ml}$ of acetic anhydride, and $2 \mathrm{ml}$ of concentrated sulphuric acid were added. The formation of violet to blue or green color shows the presence of steroids.

\section{Test for terpenoids}

$1 \mathrm{ml}$ of extract, $2 \mathrm{ml}$ of chloroform, and 3-5 drops of sulphuric acid were added. Theformation of the reddish-brown ring indicates the presence of terpenoids.

\section{Test for flavonoids}

$1 \mathrm{ml}$ of extract sample, few drops of dilute ammonium solution, and few drops of concentrated hydrochloric acid were added. The yellowish color indicates the presence of flavonoids.

\section{Test for saponins}

$1 \mathrm{ml}$ of extract and $5 \mathrm{ml}$ of distilled water were added and mixed strenuously. The formation of froth desired the presence of saponins.

\section{Test for phenols}

$1 \mathrm{ml}$ of extract sample and $1 \mathrm{ml}$ of lead acetate solution were used. The formation of a precipitate shows the presence of phenols.

\section{Test for amino acids}

$1 \mathrm{ml}$ of extract sample and 3 to 4 drops of ninhydrin solution were added and then boiled in a water bath for 10 minutes. The formation of purple or blue color indicates the presence of amino acids.

\section{Test for reducing sugars}

$1 \mathrm{ml}$ of extract and equal quantities of Fehling solution A and B were added and then heated. The formation of brick-red precipitate reveals the presence of reducing sugars.

\section{Antimicrobial Activity}

\section{Evaluation techniques:}

The assessment impact of Adhatoda vasica was finalized by the accompanying strategies:

- $\quad$ Turbidometry strategy

- $\quad$ Agar streak weakening strategy

- $\quad$ Serial weakening strategy

- $\quad$ Agar dispersion strategy

Following strategies were utilized as agar dispersion strategy:

- Agar Cup strategy

- Agar Trench strategy

- $\quad$ Paper Plate strategy 
- We have utilized the Stock Weakening Strategy to assess the antibacterial action. It is one of the non-mechanized in vitro bacterial affectability tests. This exemplary strategy yields a quantitatively result for the quantity of antimicrobial specialist expected to repress the development of explicit microorganisms.

- Macrodillution strategy in Cylinders

- Microdillution design utilizing plastic plate

- Micro Stock weakening strategy:

- $\quad$ All MTCC societies were tried against known and obscure medications.

- Mueller Hinton stock was utilized as a supplement medium to develop the medication suspension for the testing microorganisms.

- Inoculum size for test strain was conformed to 108 cfu [colony framing unit] per milliliter by looking at the turbidity.

- Natural standard strains were used to screen for antibacterial and antifungal properties:

- $\quad$ To decide the insignificant inhibitory focus (IC50) esteem. The rate (\%) of the Growth inhibition was resolved as $[(\mathrm{Ac}-\mathrm{At}) / \mathrm{Ac}] \times 100$.

- The IC50 esteem is determined utilizing the direct connection between the inhibitory likelihood and fixation logarithm as per the strategy. The IC50 esteem is communicated as the mean \pm standard deviation of three autonomous investigations.

\section{Minimum Inhibitory Concentrations (MIC)}

1. Serial weakening was set up in essential and optional screening.

2. The control tube containing no anti-microbial was promptly sub-cultured [before inoculation] by spreading a loopful over a fourth of the plate of the medium, reasonable for the development of the test microorganisms, followed by short term incubation at $370 \mathrm{C}$ for hatching

3. The MIC of the control life form was perused to check the exactness of the medication fixations.

4. The least focus repressing development of the creature was recorded as the MIC.

5. Before hatching, the measure of development from the control tube [which addresses the first inoculum]

6. Strategies used for essential and optional screening:

Essential screening:

Centralizations of combined medications were taken (1000 miniature $/ \mathrm{ml}, 500$ miniature $/ \mathrm{ml}$, and 250 miniature $/ \mathrm{ml}$ ). The combination medications found in this essential screening were also tested in the second arrangement of weakening against all microorganisms.

Optional screening: The medications discovered dynamically in essential screening were likewise weakened.

\section{Results}

The preliminary phytochemical screening was carried out on the ethanolic crude leaves extracts of Adhatoda vasica (Table 1). Phytochemical results revealed the presence of various bioactive auxiliary metabolites in leaf ethanol concentrates of Adhatoda vasica. The most extreme auxiliary metabolites were seen in ethanolic extracts. Table 1 and 2 show preliminary analysis and antibacterial and antifungal activity of leaf extract of Adhatoda vasica. Table 3 shows 
minimal bactericidal concentration and minimal fungicidal concentration of standard drugs on specific microorganisms

Table 1

Preliminary Phytochemical Analysis of Leaves Extracts of Adhatoda vasica

\begin{tabular}{lll}
\hline Sr. no. & Phytochemical analysis & Ethanol \\
\hline 1 & Alkaloids & Positive \\
2 & Steroids & Positive \\
3 & Flavonoids & Negative \\
4 & Terpenoids & Positive \\
5 & Saponins & Positive \\
6 & Phenols & Positive \\
7 & Amino acids & Negative \\
8 & Reducing sugar & Negative \\
\hline
\end{tabular}

Table 2

Antibacterial Activity and Antifungal Activity of Adhatoda Vasica, Minimal Inhibition Concentration (microgram/ml), (MTCC- microbial type culture collection)

\begin{tabular}{|c|c|c|c|c|c|c|c|}
\hline \multirow{2}{*}{$\begin{array}{c}\text { Micro- } \\
\text { organism }\end{array}$} & \multicolumn{4}{|c|}{ Bacteria } & \multicolumn{3}{|c|}{ Fungi } \\
\hline & $\begin{array}{c}E . \\
\text { coli }\end{array}$ & $\begin{array}{c}P . \\
\text { aeruginosa }\end{array}$ & $\begin{array}{c}S . \\
\text { aureus }\end{array}$ & $\begin{array}{c}S . \\
\text { Pyogenus }\end{array}$ & $\begin{array}{c}C . \\
\text { Albicans }\end{array}$ & $\begin{array}{c}A . \\
\text { niger }\end{array}$ & $\begin{array}{c}A . \\
\text { clavatus }\end{array}$ \\
\hline Code & $\begin{array}{c}\text { MTCC } \\
443\end{array}$ & $\begin{array}{c}\text { MTCC } \\
1688\end{array}$ & $\begin{array}{c}\text { MTCC } \\
96\end{array}$ & $\begin{array}{c}\text { MTCC } \\
442\end{array}$ & $\begin{array}{c}\text { MTCC } \\
227\end{array}$ & $\begin{array}{c}\text { MTCC } \\
282\end{array}$ & $\begin{array}{c}\text { MTCC } \\
1323\end{array}$ \\
\hline $\begin{array}{c}\text { Adhatoda } \\
\text { vasica extract }\end{array}$ & $\begin{array}{c}62.5 \\
\mu \mathrm{g} / \mathrm{ml}\end{array}$ & $\begin{array}{c}100 \\
\mu \mathrm{g} / \mathrm{ml}\end{array}$ & $\begin{array}{c}50 \\
\mu \mathrm{g} / \mathrm{ml}\end{array}$ & $\begin{array}{c}25 \\
\mu \mathrm{g} / \mathrm{ml}\end{array}$ & $\begin{array}{c}500 \\
\mu \mathrm{g} / \mathrm{ml}\end{array}$ & $\begin{array}{c}1000 \\
\mu \mathrm{g} / \mathrm{ml}\end{array}$ & $1000 \mu \mathrm{g} / \mathrm{ml}$ \\
\hline
\end{tabular}

Table 3

Minimal Bactericidal Concentration and Minimal Fungicidal Concentration of Standard Drugs on Specific Microorganisms

\begin{tabular}{|l|c|c|c|c|c|c|c|}
\hline \multirow{5}{*}{ Drug } & $\begin{array}{c}E . \\
\text { coli }\end{array}$ & $\begin{array}{c}P . \\
\text { aeruginosa }\end{array}$ & $\begin{array}{c}\text { S. } \\
\text { Aureus }\end{array}$ & $\begin{array}{c}\text { S. } \\
\text { pyogenus }\end{array}$ & $\begin{array}{c}\text { C. } \\
\text { Albicans }\end{array}$ & $\begin{array}{c}\text { A. } \\
\text { niger }\end{array}$ & $\begin{array}{c}\text { A. } \\
\text { clavaus }\end{array}$ \\
\cline { 2 - 8 } & $\begin{array}{c}\text { MTCC } \\
443\end{array}$ & $\begin{array}{c}\text { MTCC } \\
1688\end{array}$ & $\begin{array}{c}\text { MTCC } \\
96\end{array}$ & $\begin{array}{c}\text { MTCC } \\
442\end{array}$ & $\begin{array}{c}\text { MTCC } \\
227\end{array}$ & $\begin{array}{c}\text { MTCC } \\
282\end{array}$ & $\begin{array}{c}\text { MTCC } \\
1323\end{array}$ \\
\cline { 2 - 9 } & \multicolumn{7}{|c|}{$(\mu \mathrm{g} / \mathrm{ml})$} \\
\hline Gentamycin & 0.05 & 1 & 0.25 & 0.5 & - & - & - \\
\hline Ampicillin & 100 & 100 & 250 & 100 & - & - & - \\
\hline Chloramphenicol & 50 & 50 & 50 & 50 & - & - & - \\
\hline Ciprofloxacin & 25 & 25 & 50 & 50 & - & - & - \\
\hline Norfloxacin & 10 & 10 & 10 & 10 & - & - & - \\
\hline Nystatin & - & - & - & - & 100 & 100 & 100 \\
\hline Greseofulvin & - & - & - & - & 500 & 100 & 100 \\
\hline
\end{tabular}

\section{Observations}

Gentamycin showed growth inhibition at $0.05 \mathrm{ug} / \mathrm{ml}$ on E.coli, followed by chloramphenicol (inhibition halo at $50 \mathrm{ug} / \mathrm{ml}$ on $S$. aureus), ciprofloxacin (inhibition at $25 \mathrm{ug} / \mathrm{ml}$ on E. coli and P. aeruginosa), nystatin (inhibition at $100 \mathrm{ug} / \mathrm{ml}$ on A.niger), and greseofulvin (inhibition at $100 \mathrm{ug} / \mathrm{ml}$ on $A$. niger and $A$. clavus).

Adhatoda vasica also showed the same inhibitory activity at the same concentration on $P$. aeruginosa, S. aureus, S.pyogenus, A.niger, E.coli C. albicans. Thus, Adhatoda vasica extract might be the same as ampicillin, chloramphenicol, ciprofloxacin, nystatin, and griseofulvin. However, further cytotoxicity studies are needed to confirm these findings. 


\section{Discussion}

Since the dawn of time, medicinal plants have been utilized to treat a variety of diseases in humans. The research results provided by scientists in India on phytochemical constituents and antibacterial activity of leaf extracts are included in this review. Alkaloids, steroids, terpenoids, saponins, phenols, and reducing sugar have been found by phytochemical analysis. Adhotoda vasicagive antimicrobial activity against Staphylococcus aureus, Escherichia coli, Streptococcus Pyogenes, Pseudomonas aeruginosa, Candida albicans, Aspergillus Niger, Aspergillus clavatus have been also reported.

The presence of qualitative phytochemicals in A. vasica leaf extracts (ethanol) has been investigated [2]. The findings showed that the pure ethanol extracts of $A$. vasica leaves provided the greatest antibacterial activity against the microorganisms examined by using the agar-well diffusion method. Ample evidence exhibited that the ethanolic extract of the plant has a high antibacterial effect. The antibacterial activity of ether and aqueous extracts has been found to be poor [3]. In addition to petroleum ether and aqueous extract, the ethanolic extract should be tested for antifungal activity. Additional research on ethanolic extract could lead to the development of a good antibacterial agent. The extracts were tested for the content of phenols, tannins, alkaloids, anthraquinones, saponins, flavonoids, amino acids, and reducing sugars by using the agar well diffusion method [3]. The pure cultures of organisms, including gramnegative (Klebsiella pneumoniae and Escherichia coli) and gram-positive (Staphylococcus aureus and Enterococcus faecalis) were sub-cultured in MacConkey agar (HI Media, India) nutrient broth based on previously used method [3]. Methanol as negative and Terramycin $(30 \mu \mathrm{g} / \mathrm{l})$ as positive controls were also tested. The antimicrobial potential of leaf extraction of Adhatoda vasica leaves (Family Acanthaceae) alone has a significant contribution. The effect of a specific antimicrobial agent on the production of growth inhibition zone manifests itself as a clear area around the source of the agent [4]. It can be employed as an eco-safe, biodegradable alternative in the prevention and treatment of bacterial infections, where leaves extracts exhibited activity comparable to that of a typical antibacterial activity (i.e., ceftriaxone) against tested microbial isolates [4]. Antifungal activity of methanolic and leaf extracts of J. adhatoda, solvent against four fungi including Aspergillus niger,A. flavus, Fusarium oxysporum and Penicillium digitatumwas has been previously evaluated, where Potato Dextrose Agar Medium was applied as the medium for the evaluation of the antifungal activity by the disc diffusion method [5].

In a comparative investigation, aqueous extracts of $A$. vasica were found to be more effective against gram-negative Klebsiella pneumoniae than commercially available vasicine. The MIC and MBC values of water and ethanol extracts have been found to be promising against Klebsiella pneumoniae in plankton and biofilm forms. However, there was an unidentified activated compound in water and ethanol extract of Adhatoda vasica, showing more efficiency towards gram negative Klebsiella pneumoniae biofilm intervention than vasicine even at low MIC concentration, that are in need of further studies to know the compound in detail $[5,6]$.

The traditional use of the Justicia adhatoda appeared to be promising for treating infectious diseases, particularly bacterial and fungal infections. A study evaluated the antibacterial, antifungal, and phytochemical features of Justicia Adhatoda leaf extracts and then assessed its bioactive components. Physicochemical and Proximate analysis exhibited a $15.20 \%$ moisture 
content (leaves), and the total ash content, insoluble acid ash, water-soluble ash, and foreign matter values were found to be $11.40 \%, 1.50 \%, 3.85 \%$, and $1.68 \%$, respectively. The antibacterial and anti-fungal properties of four crude extracts of Justicia Adhatoda (petroleum ether, ethyl acetate, chloroform, methanol extracts) were studied by the aforementioned study, where all assessed organisms were slightly affected by all extracts except Pseudomonas aeruginosa and Proteus vulgaris. Among standard antibiotics used, ciprofloxacin (10 mcg/disc) and ketoconazole (10mcg/disc) showed good inhibitory effects [6, 7].

A qualitative and quantitative investigation indicated that the leaves of Adhatoda vasica contain key bioactive components such as alkaloids, steroids, terpenoids, phenols, tannins, proteins, amino acids, and saponins [8]. The methanolic extract of leaves showed a high number of phyto compounds compared with other solvents like ethanol, petroleum ether, chloroform, and aqueous. Saponins, terpenoids, and alkaloids are phytochemicals with hypoglycemic properties $[8,9]$. Many researchers evaluated the possible potential of $A$. vasica and other plants like Mentha arvensis [10-17].

The A. vasica is an excellent medicinal plant for producing $\mathrm{ZnO}-\mathrm{NPs}$ through fast $\mathrm{Zn}$ ion reduction. Since bacterial strains are resistant to traditional antibiotics, $\mathrm{ZnO}-\mathrm{NPs}$ showed a significant potential antibacterial activity against bacterial cell development; thus, they may be employed in the manufacture of apoptotic agents and the synthesis of novel antibiotics [18].

\section{Conclusion}

The current study aimed to determine the phytochemical content of Adhatoda vasica leaf extracts and to evaluate their antibacterial activity. The results indicated the existence of eight phytochemical components. The leaves of Adhatoda vasica have considerable antibacterial action against both gram-negative and gram-positive microorganisms. Antibacterial and antifungal efficacy of Adhatoda vasica against microorganisms is superior because the leaf extracts showed strong effectiveness against tested microbial isolates. Its effectiveness was comparable to that of a typical antibacterial drug (ceftriaxone). Thus, it may be employed as an eco-friendly, biodegradable alternative to prevent and treat bacterial infections.

\section{Acknowledgment}

We thank Micro care lab, Surat, for helping us in antibacterial studies.

\section{Conflict of interest}

The author declares that there is no conflict of interest.

\section{References}

[1] Sheeba JB, Selva Mohan T. Antimicrobial activity of Adhatoda vasica against clinical pathogens. Asian J Plant Sci Res.2012;2(2):83-88.

[2] Shahzad Q. Phytochemical analysis and antimicrobial activity of Adhatoda vasica Leaves. Pure Appl Biol.2020;9(2).

[3] Desai S, Patel D. Phytochemical Screening and antibacterial activity of Adhatoda vesica. Inventi J (P) Ltd.2015:37-49.

[4] Yusuf M., Adhatodavasika N. Leaves extract: phytochemical analysis and antibacterial activity. J Eng Allied Sci (IJEAS).2016:2455-2054.

[5] Sharma A, Kumar A. Antimicrobial activity of Justicia Adhatoda. World J Pharm Res.2016.

[6] Rahaman L. Extracts of Adhatoda vasica Nees. And vasicine inhibits biofilm formation of Klebsiella pneumoniae. IOSR JPBS. 2018;13(2):37-49. 
[7] Jayapriya G, Gricilda Shoba F. Phytochemical analysis, antimicrobial efficacy and determination of bioactive components from leaves of Justicia Adhatoda. Asian J Plant Sci Res.2015;5(2):43-51.

[8] Nithyatharani R, Kavitha US. Phytochemical analysis of the leaves of Adhatoda vasica. Int J Creat Res Thoughts.2018. ISSN 2320-2882.

[9] Chaudhary E, Chauhan R, Chauhan N. Assessment of bactericidal and Phytochemical Properties of Adhatoda vasica Various Extracts against gram positive and Gram-negative Bacteria. Int J Curr Microbiol Appl Sci.2017;6(7):26602669.

[10] Gheware A, Dholakia D, Kannan S, Panda L, Rani R, Pattnaik BR, Jain V, Parekh Y, Enayathullah MG, Bokara KK, Subramanian V. Adhatoda Vasica attenuates inflammatory and hypoxic responses in preclinical mouse models: potential for repurposing in COVID-19-like conditions. Respiratory research. 2021 Dec;22(1):1-5.

[11] Shilpa T, Daxa T, Mehul B. Pharmacognostical and phytochemical evaluation of Adhatoda vasica Leaf. Int J Res Stud Biosci.2014:144-148.

[12] Ramachandra YL, Ashajyothi C, Padmalatha S, Thanekar SK, Shruthi SD. Antibacterial activity of leaf Extracts of Adhatoda vasica.Int J Biomed PharmSci.2013;7(1):45-47.

[13] Rao KV, Munjal M, Patnayak A, Karthik L, Kumar G. Phytochemical composition, antioxidant, antimicrobial and cytotoxic potential of methanolic extracts of Adhatoda vasica (Acanthaceae). Res J Pharm Technol. 2013;6(9):1004-9.

[14] Aziz S, Husain H, Younis A, ur-Rehman H, Shahid M, Farooq Butt A, et al. Photochemical and biological evaluation of Jastica Adhatoda. Int J Phytomed.2017;9(1):10-14.

[15] Prakash KC, Garg SK, Yadav P, Dey A, Dey S. Studies on chromatographic finger print analysis and antibacterial activity of Adhatoda vasica leaves extracts. Pharmacology Online. 2011;3:1322-9.

[16] Gupta AK, Ahirwar NK, Shinde N, Choudhary M, Rajput YS, Singh A. Phytochemical screening and antimicrobial assessment of leaves of Adhatoda vasica, Azadirachta indica and Datura stramonium. Uk J Pharm Biosci.2013;1(1):42-47.

[17] Disha Patel,Vijay Upadhye, Tarun K Upadhyay, Esha Rami, Rakeshkumar Panchal. Phytochemical Screening and Antimicrobial Activity of Mentha Arvensis L. [Pudina]: A Medicinal Plant. Canadian Journal of Medicine. 2021;2:6776

[18] Bhumi G, Raju YR, Savithramma N. Screening of zinc oxide nanoparticles for cell proliferation synthesized through Adhatoda vasica nees. Int J Drug Dev Res.2014;6(2):97-104. 